\section{P14 THERAPEUTIC BENEFIT OF MEPOLIZUMAB IN THE NATIONAL INSTITUTE OF HEALTH AND CARE EXCELLENCE (NICE) SUB-POPULATION- A POST-HOC META-ANALYSIS OF PHASE IIB/III TRIALS}

H Marwaha, CEA Hartmann, RA Mehta, NB Gunsoy, FC Albers. GlaxoSmithKline, Research Triangle Park, NC, US

\subsection{6/thoraxjnl-2017-210983.156}

Rationale NICE provide evidence-based recommendations and guidance to the NHS regarding newly licensed drugs. Positive guidance for the use of mepolizumab, an anti IL-5 mAb, was issued for adults with severe refractory eosinophilic asthma in a sub-population who 1 ) have had eosinophils of $\geq 300$ cells per microlitre $\left(0.30 \times 10^{9} / \mathrm{L}\right)$ within the previous twelve months, and 2) have had $\geq 4$ asthma exacerbations needing systemic corticosteroids in the previous 12 months, or have had continuous oral corticosteroids (of at least the equivalent of prednisolone $5 \mathrm{mg}$ /day) for six months previously. A posthoc meta-analysis of 3 pivotal phase III studies was done to inform healthcare professionals' understanding of mepolizumab's efficacy in this subgroup.

Methods Three randomised double-blind, placebo-controlled studies (DREAM [NCT01000506], MENSA [NCT01691521], SIRIUS [NCT01691508]), using the licensed $100 \mathrm{mg}$ SC dose or the bioequivalent $75 \mathrm{mg}$ IV dose of mepolizumab, were identified. Both treatment arms were combined for analysis purposes. Data for key outcome measures (exacerbations, asthma control, and health-related quality of life) included within these trials was analysed in the sub-population and combined using the inverse-variance method. Data from SIRIUS was included in a sensitivity analysis due to differences in design and inclusion criteria from DREAM and MENSA.

Results 228 patients were included in the meta-analysis from DREAM and MENSA, 289 including SIRIUS. The mean patient age was 52.1 and 51.4 years, respectively, with a respective $60 \%$ and $61 \%$ female. In the meta-analysis of the UK NICE-specific subpopulation of DREAM and MENSA, a 53\% (95\% CI: $0.36,0.62 ; \mathrm{p}<0.001)$ reduction in clinically significant exacerbations was seen, with a $49 \% \quad(95 \%$ CI: $0.01,0.64, \mathrm{p}<0.001)$ reduction including sensitivity analysis with SIRIUS. An improvement in ACQ score of $-0.50(95 \%$ CI: $-0.73,-0.27 ; \mathrm{p}<0.001)$ and -0.53 (95\% CI: -0.73 , $-0.33 ; \mathrm{p}<0.001)$ was observed, respectively. SGRQ was used as an outcome measure in MENSA and SIRIUS only, showing an improvement in score of -7.3 (95\% CI: $-11.1,-3.5$, $\mathrm{p}<0.001)$.

Conclusion In the NICE sub-population, mepolizumab showed clinically meaningful and statistically significant effectiveness. These Results aim to inform UK healthcare professionals' understanding of the likely treatment effect of mepolizumab in this sub-population.

Funding GSK (NCT01000506, NCT01691521, NCT01691508).

\section{P15 COST EFFECTIVENESS OF MEPOLIZUMAB FOR SEVERE EOSINOPHILIC ASTHMA FROM THE UK PERSPECTIVE}

${ }^{1} \mathrm{~S}$ Doyle, ${ }^{2} \mathrm{~K}$ Westerhout, 'S Cockle, ${ }^{1} \mathrm{~N}$ Gunsoy, ${ }^{2} \mathrm{~B}$ Verheggen. ${ }^{1}$ GlaxoSmithKline, London, UKi ${ }^{2}$ Pharmerit, Rotterdam, Netherlands

10.1136/thoraxjnl-2017-210983.157
Introduction Severe asthma patients have limited therapeutic options. These patients remain at risk of exacerbations, their quality of life is negatively impacted and they place a significant burden on the health service. Mepolizumab is licensed for use in patients with severe eosinophilic asthma. As reimbursement authorities expect evidence of health economic benefits, this study aimed to estimate the cost-utility of mepolizumab as an add-on therapy to standard of care (SOC) versus SOC alone.

Methods A de novo Markov cost-utility model was produced which compared the costs and outcomes of mepolizumab vs. SOC over a lifetime horizon. Primary analysis was based on data from the MENSA clinical trial (NCT01691521). Patients entering the model were assigned to mepolizumab or SOC and experienced treatment-specific probabilities of exacerbation events with an associated risk of mortality and disutility. The model included a continuation criteria where patients on mepolizumab who failed to demonstrate an exacerbation reduction were transitioned to the SOC arm. Costs and health outcomes were discounted annually at $3.5 \%$. The model did not account for indirect costs or value in steroid reduction.

Results In the basecase analysis (patients with $\geq 300$ eosinophil cells/ $\mu \mathrm{L}$ and $\geq 4$ exacerbations in the previous 12 months) the incremental cost-effectiveness ratio (ICER) of add-on mepolizumab compared with SOC was $£ 30,268$ /QALY gained. Scenario analyses showed that the ICER was sensitive to the starting age of the cohort, the source of utility and asthma-related mortality.

Conclusion Mepolizumab represents a clinically efficacious and cost-effective alternative to SOC.

\section{P16 IMPLICATIONS OF NICE GUIDANCE IN ENGLAND AND WALES ON ELIGIBILITY FOR TREATMENT WITH MEPOLIZUMAB AND OMALIZUMAB - AN IDEAL STUDY ANALYSIS}

CEA Hartmann, H Starkie Camejo, NB Gunsoy, RA Mehta, FC Albers. GlaxoSmithKline, Research Triangle Park, NC, US

\subsection{6/thoraxjn|-2017-210983.158}

Rationale Severe asthma (SA) patients are a heterogeneous population with diverse clinical characteristics and biomarkers, including eosinophils and IgE. It is of clinical relevance to understand the relationship between different severe asthma phenotypes and thus eligibility for biologic therapies. The IDEAL study (Identification and Description of Severe Asthma Patients in a Cross-Sectional Study) aimed to define the proportion of patients in England and Wales who are eligible for anti IL-5 (mepolizumab) or anti-IgE (omalizumab) targeted therapy, and those who may be eligible for both, given current NICE guidance.

Methods IDEAL, an observational study, included SA subjects aged $\geq 12$ years defined according to ATS/ERS guidelines by treatment with high-dose ICS plus additional controller(s) for $\geq 12$ months. A post hoc analysis of IDEAL was conducted to identify eligibility to mepolizumab and omalizumab in accordance with current NICE guidance for each. Mepolizumab eligibility was defined as per NICE guidance: 'severe refractory eosinophilic asthma patients who have eosinophils $\geq 300$ cells/microlitre $\left(0.30 \times 10^{9} / \mathrm{L}\right)$ or more in the previous 12 months and have had $\geq 4$ asthma exacerbations needing systemic corticosteroids in the previous 12 months, or 
have had continuous oral corticosteroids of at least the equivalent of prednisolone $5 \mathrm{mg}$ per day for the previous 6 months'. Omalizumab eligibility defined as 'evidence of severe persistent allergic asthma and need for continuous or frequent treatment with oral corticosteroids (defined as $\geq 4$ courses in the previous year), and meeting bodyweight and $\operatorname{IgE}$ criteria for omalizumab treatment'.

Results Of 748 SA subjects enrolled in the study, 670 met the analysis criteria and were included in this post-hoc analysis (mean age $=50.9$ years; 62\% female). 90 subjects (13\%) were eligible for mepolizumab and $184(27 \%)$ were eligible for omalizumab. Of the 90 mepolizumab eligible patients, 31 $(5 \%)$ were receiving omalizumab therapy, while of the remaining $59(9 \%)$ patients not on a biologic $11(2 \%)$ were also eligible for omalizumab.

Conclusions This is the first cross-sectional study providing estimation of the proportion of SA patients eligible for biologic therapy in accordance with NICE guidance, indicating $13 \%$ mepolizumab-eligibility and $27 \%$ omalizumab-eligibility with limited overlap. (Funded by GSK; 201 722.)

\section{P17 MONITORING INHALED CORTICOSTEROID ADHERENCE OF PATIENTS ON OMALIZUMAB IN A REAL WORLD COHORT}

LJ Holmes, R Daly, K Hince, C Ustabashi, DJ Allen. University Hospital of South Manchester, Manchester, UK

10.1136/thoraxjnl-2017-210983.159

Background

- Omalizumab (Xolair) is licensed for the treatment of severe allergic asthma patients with IgE mediated disease.

- Within the UK NICE guidance includes criteria for documented adherence to Inhaled Corticosteroids (ICS) and other asthma related medications.

- Within the UK there is no clear definition of 'documented compliance' Within the Severe Asthma North West MDT this is defined as $\mathrm{a} \geq 80 \%$ collection of ICS based on GP data.

Objective To assess adherence to ICS treatment for patients on Omalizumab therapy and to explore causal relationships and outcomes between the adherent and non-adherent groups.

Methods Over a 2 week period in Feb 2017 patients attending for routine Omalizumab care (post 16 week assessment) underwent standard observations (FEV1, FeNO and ACQ-7) additionally each patient was asked to clarify the type and frequency of current ICS and adherence data was obtained from the patients GP for the last 6 months.

Results Of 79 patients (67.1\%) were female and (32.9\%) were male, with a mean age of 50.7 (SD 14.12). ICS adherence was observed in 39 (49.4\%) of patients. Comparison between the two groups (Table 1), demonstrates little difference between both groups. The adherent group have a lower baseline FEV1 (55\%) and FeNO (15.5 ppb) compared to the nonadherent group $(61.9 \%$ and $22.0 \mathrm{ppb})$, and demonstrate a higher percentage change in FEV1 from baseline $(8.3 \%$ compared to $5.67 \%)$. Both groups demonstrate a significant improvement in ACQ-7 from baseline, and there was a trend $(p=0.067)$ for better control (lower ACQ-7 score) in the nonadherent group.

Conclusion

- Non adherence to ICS in patients on Omalizumab therapy is a significant issue.
- There were no significant differences between the 2 groups in terms of exacerbations or ICS treatment regimes.

- There was a statistical, but not clinically significant rise in FeNO in the non-adherent group.

- There was a trend towards better perceived asthma control as measured by the ACQ-7 in the non-adherent group which may influence ongoing adherence to ICS.

\section{REFERENCE}

1. Asthma Control Questionnaire. https://www.qoltech.co.uk/acq.html

\begin{tabular}{|c|c|c|c|}
\hline & $\begin{array}{l}\text { Adherent group } \\
(>76 \%)\end{array}$ & $\begin{array}{l}\text { Non-adherent group } \\
(0 \%-75 \%)\end{array}$ & Test statistic \\
\hline $\begin{array}{l}\text { Baseline } \% \\
\text { Fev1 }\end{array}$ & 55.00 (SD 15.72) & 61.95(SD 22.61) & $\begin{array}{l}\text { ANOVA } F=1.317, d f=1, \\
p=0.258\end{array}$ \\
\hline Current $\%$ Fev1 & 65.71 (IQR 37.00) & 69.85 (IQR 28.00) & $\begin{array}{l}\text { Mann-Whitney } U=507 \text {, } \\
p=0.387\end{array}$ \\
\hline $\begin{array}{l}\text { Current FeNO } \\
(\mathrm{ppb})\end{array}$ & 15.50 (IQR 14.75) & 22.00 (IQR18.75) & $\begin{array}{l}\text { Mann-Whitney } U=158.0 \text {, } \\
p=0.048\end{array}$ \\
\hline $\begin{array}{l}\text { Baseline ACQ- } \\
7\end{array}$ & 3.85 (IQR 2.00) & 2.85(IQR 1.72) & $\begin{array}{l}\text { Mann-Whitney } U=20.00 \text {, } \\
p=0.397\end{array}$ \\
\hline $\begin{array}{l}\text { Current ACQ- } \\
7\end{array}$ & 2.36 (SD 1.60) & 1.79 (SD 1.02) & $\begin{array}{l}\text { ANOVA } F=3.448, d f=1, \\
p=0.067\end{array}$ \\
\hline $\begin{array}{l}\text { BDP } \\
\text { equivalent }\end{array}$ & 2000 (IQR 1000) & 1600 (IQR1200) & $\begin{array}{l}\text { Mann-Whitney } \\
U=502.50, p=0.039\end{array}$ \\
\hline
\end{tabular}

\section{P18 EARLY EXPERIENCE INITIATING MEPOLIZUMAB FROM NICE TO THE REAL WORLD}

U Holmes, L Elsey, R Niven. University Hospital of South Manchester, Manchester, UK

\subsection{6/thoraxjnl-2017-210983.160}

Objective To identify barriers which prevent patients meeting the NICE criteria for mepolizumab.

Background Mepolizumab is a steroid sparing agent for patients with severe eosinophilic asthma. All patients must meet the $\mathrm{NICE}^{1}$ criteria:

- Eosinophil count $\geq 300$ cells/microlitre in past 12 months

- Adherence to optimised therapy

- Four or more courses of oral corticosteroids (OCS) in past 12 months or continuous OCS equivalent to at least $5 \mathrm{mg}$ of for 6 months

Methods Adherence data was obtained from the patient's GP and eosinophil counts recorded from the hospital electronic patient records. If a patient did not meet the approval criteria the following data was collected: their current OCS dose; number of years under the severe asthma service; last eosinophil count $\geq 300$ cells/ microlitre.

Results Of the 269 patients identified as potential mepolizumab candidates 133 have been assessed and 32 (24\%) have so far been approved, 38 (28\%) have not been approved due to non-adherence to inhaled corticosteroid (ICS) therapy. In this cohort the average ICS adherence was 47\% ( \pm SD 0.23) and time under severe asthma specialist care equates to 6.1 years ( \pm 3.6$) .63(51 \%)$ patients did not have an eosinophil count $\geq 300$ cells/microlitre in the last 12 months. In this 